\title{
Variations in the Course of the Inferior Gluteal Nerve and Artery: A Case Report and Literature Review
}

\author{
Jun Yan, Masaki Takechi, Jiro Hitomi \\ Department of Anatomy, School of Medicine, Iwate Medical University, Iwate, Japan \\ Email: junyan@iwate-med.ac.jp
}

Received September 2, 2013; revised October 1, 2013; accepted October 8, 2013

Copyright (C) 2013 Jun Yan et al. This is an open access article distributed under the Creative Commons Attribution License, which permits unrestricted use, distribution, and reproduction in any medium, provided the original work is properly cited.

\begin{abstract}
Variations in the course of the inferior gluteal nerve and artery were observed in Japanese cases (4/94 sides). In these variation cases, the inferior gluteal nerve exited the pelvis from the upper edge of the piriformis (suprapiriformis foramen) in $4 / 4$ sides (4.26\%). In 2/4 sides (2.13\%), the normal inferior gluteal artery was not observed, except that a fine artery exited the pelvis from the inferior piriformis foramen to form an "arch" with the superior gluteal artery under the gluteal maximus in 1/4 side. Moreover, in 1/4 side, a twig of the internal pudendal artery exited pelvis from inferior piriformis foramen and distributed to the surrounding tissues. The present observations of the inferior gluteal nerve and artery course are very important and useful for surgeons and nurses.
\end{abstract}

Keywords: Inferior Gluteal Nerve; Inferior Gluteal Artery; Suprapiriformis Foramen; Variation; Human

\section{Introduction}

Anatomy textbooks show that the inferior gluteal nerve (IGN) and artery (IGA) perforate below the piriformis (infrapiriformis foramen [IPF]), exit the pelvis, and distribute primarily to the gluteus maximus [1-3]. However, cases of IGN variation have been reported [4,5]. Recently, the nerve and artery were investigated for clinical treatments, such as skin flap surgery, IGN, aneurysms, and imaging diagnosis [6-10]. Therefore, it is useful to examine the basic clinical data of the IGN and IGA that exit the pelvis from the upper edge of the piriformis (suprapiriformis foramen [SPF]).

In the most recent detailed investigation of the relation between the IGN and piriformis muscle, Chiba advocated (in Japanese) that this relation should be classified into XIII types, although the IGA was not mentioned [5]. However, such a complex classification of this relation is useless in the clinical setting. Therefore, the purpose of this report was 1) to focus on the IGN that exits the pelvis from the SPF only and to compare the percentages of the nerve(s) that pass through the SPF in the literature, and 2) to discuss the IGA supplying the gluteus maximus by passing through the course variation.

\section{Observations}

Variations in the course of the IGN and IGA were observed in 4 sides in cadavers during the 2012 and 2013 dissection courses at Iwate Medical University School of Medicine ( 47 bodies; fixed with $10 \%$ formalin through the radial artery and preserved in 50\% alcohol for 6 months). The cadavers were handled in compliance with the ethical guidelines of Iwate Medical University.

\subsection{The Inferior Gluteal Nerve}

As shown in Figure 1, after amputating the insertion of the gluteus maximus, the nerve and artery innervating the muscle were observed. The nerves (superior and inferior gluteal nerves) that perforated the upper edge of the piriformis (SPF) exited the pelvis. The common fibular nerve (CFN) also exited the pelvis from the SPF. The tibial nerve exited the pelvis through the normal course, namely the IPF. In 1 case, the CFN as a single nerve accompanied by the tibial nerve exited the popliteal fossa, and in the other cases the CFN and the tibial nerve constituted the sciatic nerve at the lower level of the piriformis. The variation nerve distributed segmentally to gluteus maximus from the lumbosacral trunk (LST), S1S3.

\subsection{The Inferior Gluteal Artery}

In 2 cases, the artery distributed to the gluteus maximus from the superior gluteal artery (SGA) only (Figures 2 and 3), which was anastomosed with the medial circumflex femoral artery under the gluteus maximus. In 1 case, 


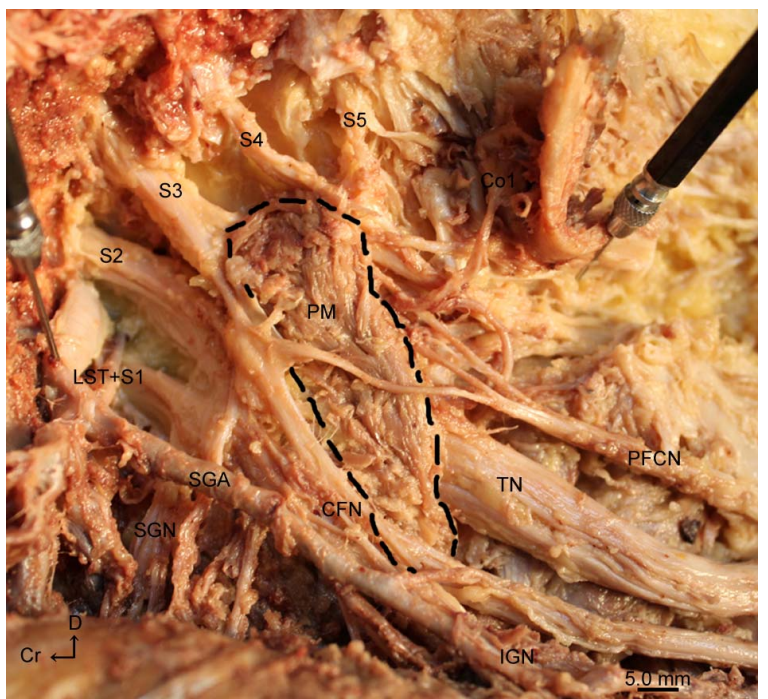

Figure 1. A photo (posterior view) showing the inferior gluteal nerve (IGN) exited the pelvic from upper edge of the piriformis muscle (PM) with the common fibula nerve (CFN). The tibia nerve (TN) was from normal course exited the pelvic and the posterior femoral cutaneous nerve (PFCN) was from both upper and low edge of piriformis muscle. The superior gluteal artery (SGA) was the main artery supplying the gluteus maximus muscle.

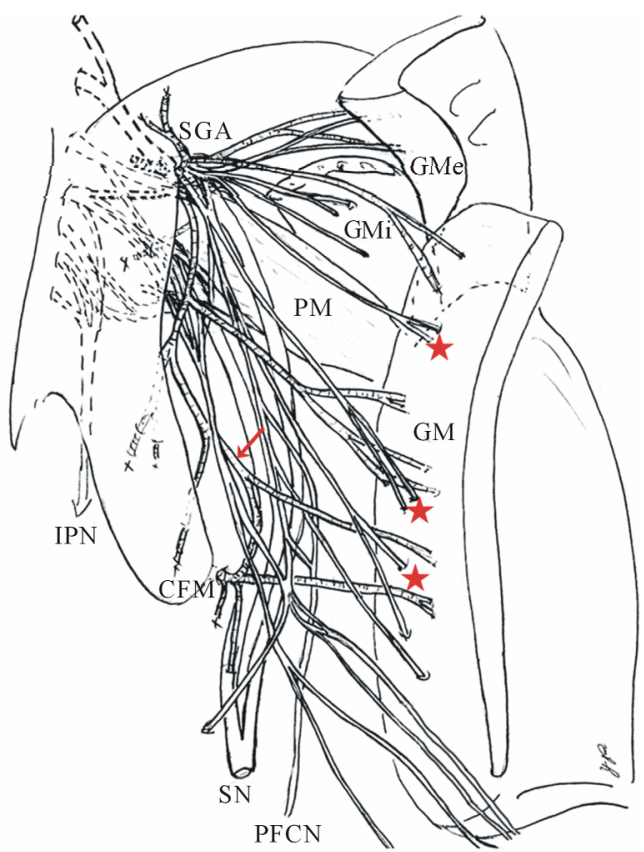

Figure 2. A sketch (posterior view) showing the nerve and artery supplying gluteal maximus muscle exited the pelvic from upper edge of piriformis muscle, and the artery anastomosis with the medial circulation femoral artery to form an "arch" under the gluteal maximus (Red arrow). Note the normal inferior gluteal artery was absence. GM: gluteal maximus; GMe: gluteal medius; GMi: gluteal minimus; SN: sciatic nerve; Red star mark: the nerves innervating gluteal maximus exited the pelvic from upper edge of pirifomis muscle.

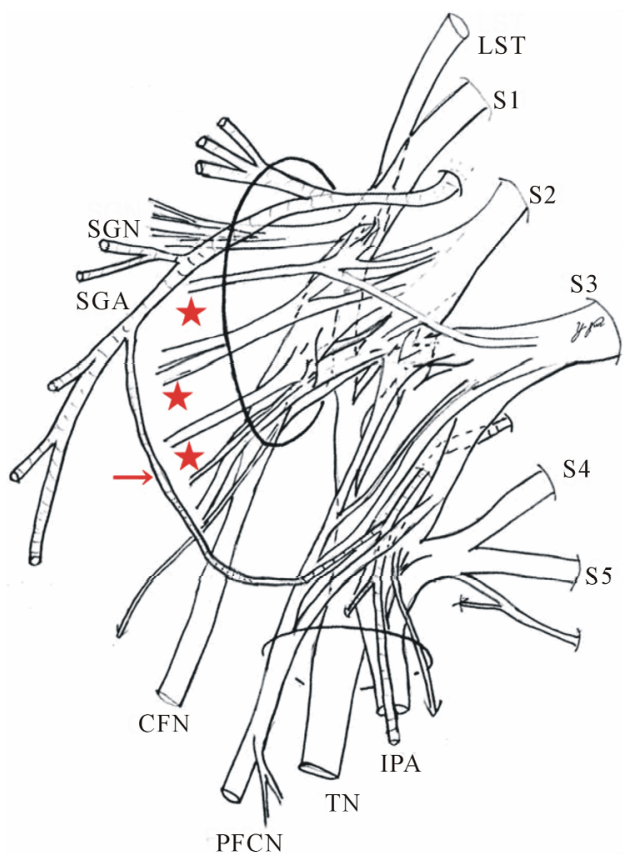

Figure 3. A sketch showing the form of the sacral plexus (posterior view). The nerves innervating gluteal maximus exited the pelvic from upper edge of pirifomis (Red star mark). Under the gluteal maximus, an "artery arch" (Red arrow) was formed by the superior gluteal artery and a twig from internal pudendal artery (IPA). The normal inferior gluteal artery was absence.

the IGA was very fine and anastomosed with the SGA under the gluteus maximus to form an "arch". In another case, a fine branch exited the pelvis from the IPF, but was a twig of the internal pudendal artery; this twig branched into the surrounding tissue.

\section{Discussion}

The course of the IGN and IGA is important for clinical treatment, such as in plastic surgery, grafting surgery, and clinical nursing [11-14]. However, many variations in the courses of the IGN and IGA have been observed and discussed [15-18], although the IGA was not discussed $[5,19,20]$.

In the literature, the relative frequencies of the IGN exiting the pelvis from the upper edge of the piriformis in human adults were $1.4 \%(8 / 579)$ [15]; $0.4 \%(1 / 246)$ [16]; $0.4 \%(1 / 284)$ [21]; $2.1 \%(3 / 144)$ [22]; $1.0 \%(3 / 306)$ [23]; $3.3 \%(4 / 120)$ [24]; $4.4 \%(14 / 320)$ [17]; $1.9 \%(2 / 106)$ [25]; $2.0 \%(4 / 200)$ [26]; $0.9 \%(1 / 112)$ [27]; and $0.2 \%$ $(1 / 257)$ [5]. This frequency in fetuses was $0.4 \%(1 / 240)$ [28]; $1.2 \%(2 / 164)$ [29]; $1.1 \%(4 / 364)$ [30]; and 2.0\% $(4 / 200)$ [31]. In our series, this frequency in adults was $4.26 \%$ (4/94), which was closer to that reported by Hasimoto and Toyama (1942). Variations in the course of the IGN are closely related with the generation of the piriformis muscle [5], thus it is likely that the IGN fibers 
changed course and transferred it with the SGN to exit the pelvis from the SPF.

Generally, the IGA branches from the internal iliac artery, passes through the lower edge of the piriformis, and distributes to the lower part of the gluteus maximus; the arteries supplying the gluteus maximus are derived from both the SGA and IGA. In the literature, the IGA has been indicated to originate from the internal pudenda artery (IPA) or further from the obturator artery [4], and the absence of the IGA has been reported in 1 case [32]. Recently, superior and inferior gluteal artery perforator flaps (SGAP and IGAP) have been used for transplantation surgery. On the other hand, it has been mentioned that a descending branch of the IGA is an important vessel for the flap and was present in 91\% of patients; however, the authors did not mention whether the IGA was absent or exited the pelvis from the SPF [7]. Gabrielli et $a l$. investigated this artery in 80 sides in humans and reported that none exited the pelvis from the upper edge of the piriformis [6]. The present observation indicated that the artery supplying the gluteus maximus muscle could originate from the SGA only and/or from other branches, in agreement with the individual results of Bergman and Reddy $[4,32]$. Therefore, the variation in the course of the artery and the rare occurrence of the IGA being a twig to form an "arch" under the gluteus maximus are clinically important.

Moreover, present variation cases show that the variation of inferior gluteal nerve accompanies with the variation of the artery in all cases is effected by unknown mechanism in early stage of generation. Therefore, further investigations of the embryological changes in the nerves and arteries distributed to gluteus muscle group are necessary.

\section{Conclusions}

The relative frequency of the inferior gluteal nerve exiting the pelvis from the upper edge of the piriformis ranges from $0.2 \%$ to $4.4 \%$ in human adults and $0.4 \%$ to $3.2 \%$ in fetuses. In our series, this frequency was $4.26 \%$ in Japanese adults.

The inferior gluteal artery could be absent or present as a very fine anastomosis twig that forms an "arch" with the superior gluteal artery under the gluteus maximus.

\section{Acknowledgements}

We thank Mr. S. Takahashi and Mr. N. Sasaki (Iwate Medical University) for their technical advice. This work was supported financially by the Advanced Medical Science Center of Iwate Medical University.

\section{REFERENCES}

[1] P. E. Celli, "Sulla Morphologie del M. Piriformis,"
Anatomischer Anzeiger, Vol. 41, 1913, pp. 551-560. http://www.biodiversitylibrary.org/item/43338\#page/579/ mode/1up

[2] G. Gabella, “Gray’s Anatomy,” In: P. L. Williams, Ed., Pelvic Girdle and Lower Limb, 38th Edition, Churchill Livingstone, New York, 1995, pp. 1545-1564.

[3] V. Mahadevan, “Gray’s Anatomy,” In: S. Standing, Ed., Pelvic Girdle and Lower Limb, 40th Edition, Churchill Livingstone, New York, 2008, pp. 1329-1390.

[4] R. A. Bergman, S. A. Thomson, A. K. Afifi and F. A. Saadesh, "Compendium of Human Anatomic Variations," Urban \& Schwarzenberg, Baltimore, Munich, 1988, pp. 84-85.

[5] S. Chiba, "Multiple Positional Relationships of Nerves Arising from the Sacral Plexus to the Piriformis Muscle in Human,” Journal of Anatomy, Vol. 67, No. 6, 1992, pp. 691-724. (in Japanese)

[6] C. Gabrielli, E. Olave, A. Sarmento, C. Mizusaki and J. C. Prates, "Abnormal Extrapelvic Course of the Inferior Gluteal Artery,” Surgical and Radiologic Anatomy, Vol. 19, No. 3, 1997, pp. 139-142.

http://dx.doi.org/10.1007/BF01627962

[7] C. Windhofer, E. Brenner, B. Moriggl and C. Papp, "Relationship between the Descending Branch of the Inferior Gluteal Artery and the Posterior femoral Cutaneous Nerve Applicable to Flap Surgery," Surgical and Radiologic Anatomy, Vol. 24, No. 5, 2002, pp. 253-257. http://dx.doi.org/10.1007/s00276-002-0064-z

[8] Z. X. Ling and V. P. Kumar, "The Course of the Inferior Gluteal Nerve in the Posterior Approach to the Hip,” The Bone \& Joint Journal, Vol. 88-B, No. 12, 2006, pp. 1580 1583. http://dx.doi.org/10.1302/0301-620X.88B12.18182

[9] F. S. Anthony, F. M. Michael, W. Gary and B. Kath, "Relationship of Inferior Gluteal Nerve and Vessels: Target for Application of Stimulation Devices for the Prevention of Pressure Ulcers in Spinal Cord Injury", Surgical and Radiologic Anatomy, Vol. 30, No. 1, 2008, pp. 41-45. http://dx.doi.org/10.1007/s00276-007-0282-5

[10] S. Mariano and D. M. Gilda, "Exposure of the Sciatic Nerve in the Gluteal Region without Sectioning the Gluteus Maximus: Analysis of a Series of 18 Cases," Surgical Neurology International, Vol. 3, No. 1, 2012, pp. 1520. http://dx.doi.org/10.4103/2152-7806.92929

[11] G. C. Cormack and B. G. H. Lamberty, "The Blood Supply of Thigh Skin,” Plastic \& Reconstructive Surgery, Vol. 75, No. 3, 1985, pp. 342-354. http://dx.doi.org/10.1097/00006534-198503000-00008

[12] A. Frick, R. G. H. Baumeister and B. Wiebecke, "Microvasculature of the Inferior Gluteal Flap," European Journal of Plastic Surgery, Vol. 16, No. 1, 1993, pp. 3032. http://dx.doi.org/10.1007/BF00192703

[13] M. Tarek, "Superior Gluteal Artery Perforator Flap for Closure of Large Sacral Defects," Egyptian Journal of Plastic and Reconstructive Surgery, Vol. 28, No. 2, 2004, pp. 175-179.

[14] J. A. Robert, M. L. Maria and W. G. Jay, "Inferior Gluteal Perforator Flaps for Breast Reconstruction,” Seminars in Plastic Surgery, Vol. 20, No. 2, 2006, pp. 89-94. 
http://dx.doi.org/10.1055/s-2006-941715

[15] B. Adachi, "Anatomische Untersuchungen an Japanern,” Zeitschrift für Morphologie und Anthropologie, Vol. 2, No. 2, 1900, pp. 198-222.

[16] C. R. Bardeen and A. W. Elting, “A Statistical Study of the Variations in the Formation and Position of the Lumbosacral Plexus in Man,” Anatomical Record, Vol. 19, No. 1, 1901, pp. 209-232.

[17] M. Hasimoto and K. Toyama, "The Relationship of the Sacral Nerve and Piriformis Muscle in Chinese," Acta Anatomica Nipponica, Vol. 19, No. 2, 1942, pp. 171-184. (in Japanese)

[18] G. Odajima and T. Kurihara, "Supplementary Findings to the Morphology of M. Piriformis," Journal of Showa Medical Society, Vol. 20, No. 3. 1960, pp. 1-4. (in Japanese)

[19] M. E. Tarek and H. A. Abdelghany, "Inferior Gluteal Nerve and Artery: An Anatomical Study,” Alexandria Journal of Medicine, Vol. 45, No. 2, 2009, pp. 1-17.

[20] P. S. Sharadkumar, "The Anatomical Study of Division of the Sciatic Nerve Proximal to its Exit," Mad Science, Vol. 2, No. 1, 2013, pp. 169-171.

[21] Y. Koganei, S. Arai and S. Shikinami, "The Statistics of the Variation of the Muscles," Journal of Tokyo Medical Society, Vol. 17, No. 2, 1903, pp. 127-131. (in Japanese)

[22] S. Igarashi, "The Relationship of the N. Ischiadicus and M. Piriformis," Journal of Kanazawa Medical University, Vol. 19, No. 1, 1935, pp. 123-153. (in Japanese)

[23] N. Fukumoto, “The M. Piriformis and N. Ischiadicus in Japanese," Journal of Fukuoka Medical University, Vol. 28, No. 3, pp. 756-763. (in Japanese)
[24] L. E. Beaton and B. J. Anson, "The Relation of the Sciatic Nerve and Its Subdivisions to the Piriformis Muscle," The Anatomical Record, Vol. 70, No. 1, 1938, pp. 1-5. http://dx.doi.org/10.1002/ar.1090700102

[25] T. Hayama, "The Relationship of Sciatic Nerve and Piriformis Muscle,” Journal of Medical University of Japan, Vol. 13, No. 3, 1954, pp. 1583-1588. (in Japanese)

[26] C. Nizankowski, J. Stociak and J. Szybejko, “Odimany Przebiegu Nerwu Kulszwogo u Cztowieka,” Folia Morphologica, Vol. 31, 1972, pp. 507-513.

[27] B. Tillmann, "Verlaufsvarianten des N. Gluteus Inferior," Anatomical Record, Vol. 145, No. 3, 1979, pp. 293-302.

[28] T. Kusida, "The Lumbosacral Plexus in Japanese Fetus: Part III,” Acta Anatomica Nipponica, Vol. 16, No. 1, 1941, pp. 28-47. (in Japanese)

[29] J. Sugiyama, "The Relationship of the Sciatic Nerve and Piriformis Muscle in Japanese Fetal Twins,” Anatomical Study of the Fetal Twins, Vol. 4, 1943, pp. 1-26. (in Japanese)

[30] K. Kubota, I. Noguchi and T. Nakao, "Rare Types of Relation between the Sciatic Nerve and the Piriformis Muscle,” Okajimas Folia Anatomica Japonica, Vol. 36, No. 2, 1960, pp. 329-344.

[31] K. Honma, "The Anatomical Study of Sciatic Nerve in Japanese Fetus,” Journal of Tokyo Medical University, Vol. 17, No. 4, 1959, pp. 1955-1993. (in Japanese)

[32] R. Ausencia, R. V. Venkata and R. Mohandas, "Absence of Inferior Gluteal Artery: A Rare Observation,” International Journal of Morphology, Vol. 25, No. 1, 2007, pp. 95-98. 